\title{
Adaptation Strategies for Water Resources: Criteria for Research
}

\author{
Franco Salerno \\ CNR IRSA, Water Research Institute, Via del Mulino, 19, I-20861 Brugherio (MB), Italy; salerno@irsa.cnr.it; \\ Tel.: +39-039-21694221
}

Received: 6 September 2017; Accepted: 17 October 2017; Published: 19 October 2017

\begin{abstract}
The Paris Agreement presents new fields of research related to the adaptation strategies to climate change. A challenge for future research consists in developing context-specific guidelines to support adaptation. This Special Issue on "Adaptation strategy to climate change for water resources" is born in this context. It contains 15 scientific studies facing a diversity of issues inherent to the adaptation strategies for water resources. This editorial analyses how the authors of this collection of papers decided to develop and present their research in order to identify criteria to contribute defining, in a near future, standardized approaches and practices for adaptation studies. Papers have been categorized in two major fields: "Studies for the development of adaptation scenarios" and "Studies for the development of adaptation solutions". Papers belonging to both categories are generally found missing to treat the 'uncertainty' issues arising and the implementation of the proposed adaptation strategies. Studies investigating future adaptation scenarios are generally found to be unbalanced in favor of the assessment of future impacts on water resources and less towards the provision of adaptation scenarios. When these studies do not provide elements to manage the specific uncertainty related to the proposed adaptation solutions, at least exploring the uncertainty related to the climatic and impact scenarios is strongly recommended. Studies providing methodological and/or procedural examinations on adaptation solutions are recommended to suitably report the climatic, environmental, and social context for which the action has been developed. A reduction of uncertainty and an easier implementation of proposed measures could be induced from this.
\end{abstract}

Keywords: adaptation strategies; climate change; water resources; uncertainty; implementation

\section{Introduction}

Planning for adaptation to climate change has emerged as a central component of climate policy over the last decade. The Cancun Adaptation Framework (CAF) was established at the 16th Conference of the Parties (COP) adopted in Cancun (Mexico) in 2010. The parties affirmed that "adaptation must be addressed with the same priority as mitigation" [1,2]. Under this framework, the COP invited "all Parties to enhance action on adaptation" [1-14] by "planning, prioritizing and implementing adaptation actions, including projects and programs" [1-14]. The Paris agreement (COP21) provided numerous indications and details about adaptation, mainly in Article 7 [2]. Parties should strengthen their cooperation especially for actions such as: (a) sharing information, good practices, experiences, and lessons learned, including, as appropriate, as these relate to science, planning, policies, and implementation in relation to adaptation actions; (b) strengthening institutional arrangements ... ; (c) strengthening scientific knowledge on climate, including research, systematic observation of the climate system and early warning systems in a manner that informs climate services and supports decision-making; $(\mathrm{d})$ assisting developing country parties in identifying effective adaptation practices, adaptation needs, priorities, support provided and received for adaptation actions and efforts, and challenges and gaps, in a manner consistent with encouraging good practices; and (e) improving the effectiveness and durability of adaptation actions. 
Therefore, from a research point of view, the Paris Agreement recommends: strengthening the scientific knowledge on climate system and climate services; and identifying effective adaptation needs and practices, priorities, challenges, and gaps, in a manner consistent with improving the effectiveness and durability of adaptation actions.

It is expected that the parties will introduce adaptation into their national development, and environmental plans and policies [3], but currently, the question of measuring vulnerability, adaptive capacity, and resilience is the new challenge for policy makers and scientists, and for this goal to be operationalized, more conceptual work needs to be done [4]. The fact that adaptation is so complex-being cross-sectoral and multi-dimensional with political, economic, environmental and social dimensions-has led to a great amount of work, but without proposing a common framework [5]. There is no single, universal metric that fits the reality of adaptation as there is for mitigation [6].

The scientific community is called on to help move toward a more structured approach to adaptation and more explicit targets by defining criteria to capture national adaptation efforts [7].

This Special Issue is born in face of these recommendations. It has provided the platform for researchers to present new studies on adapting strategies to climate change impacts on water resources, in order to identify and evaluate adaptation practices-areas where more knowledge is neededand to recommend possible policy-related actions that could be pursued. After a brief description of the main outputs published in this Special Issue for each paper, a discussion is proposed: an attempt to analyze how the authors decided to develop and present their research. From this analysis, some criteria emerge to define in a near future standardized approaches for adaptation studies.

\section{Contributions}

Most of the 15 papers presented in this Special Issue fall into four broad sectors: groundwaters, natural and artificial reservoirs, urban areas, and agricultural areas. Furthermore, one paper discusses policy experimentation.

\subsection{Policy Experimentation for Adapting Strategies to Climate Change}

McFadgen and Huitema (2017) wrote an interesting paper on the opportunities offered by the policy experimentation [8]. The authors implemented a survey from 173 people involved in a set of policy experiment which assessed new policy initiatives relevant to climate adaptation in the Netherlands (where climate change is a national priority). The attention of this paper is focused on how policy experiments produce learning, what types of learning they produce, and how they have to be designed to enhance learning effects. The findings show that policy experiments produce cognitive and relational learning effects, but less normative learning.

\subsection{Adapting Strategies for Groundwaters}

Guyennon et al. (2017) face the problems related to the impact of irrigation on groundwater resources: increasing demand or water scarcity caused by climate change are the main drivers leading to groundwater table depletion [9]. In many areas of the world, periodic water shortages caused by temporal imbalances between supply and demand can be faced by storing water during rainy periods for later use during dry periods. In this context, among possible adaptation measures to climate change, two are considered and compared by the authors: (1) increasing surface water retention capacity (IMC) and (2) Managed Aquifer Recharge. The second adaptation option is an engineered system where excess surface water is put on or in the ground for infiltration to aquifers to increase groundwater resource availability. The case study, where these options are compared, is located in Southern Italy, characterized by semi-arid Mediterranean climate and intensively irrigated agriculture. The authors observed that, although no significant long-term trend affects the proposed precipitation scenarios, the expected temperature increase highly impacts the resources due to the associated increase of water demand for irrigation purposes. The MAR scenario is found to be more effective than the IMC during long term wet periods (typically, five years) and successfully compensates the impact on the 
groundwater resources. The authors conclude that the MAR scenario is a suitable adaptation strategy to face the expected future changes in climate, although mitigation actions to reduce greenhouse gases are strongly required.

\subsection{Adapting Strategies for Natural and Artificial Reservoirs}

Marziali et al. (2017), Zhai et al. (2017), and Ren et al. (2017) point out the climate change implications on management of artificial reservoir [10-12]. Marziali et al. (2017) consider the problem emphasizing the water quality. The authors explain that these artificial resources are characterized by accumulation of sediments where micropollutants may concentrate, with potential toxic effects on downstream river ecosystems. Climate change is expected to increase sediment loads, but potential effects on their quality are scarcely known. In this context, sediment contamination by trace elements and organics was analyzed in 20 reservoirs located in the Italian Central Alps. The authors indicate a strong As presence and a moderate $\mathrm{Cd}, \mathrm{Hg}$, and $\mathrm{Pb}$ presence, with potential ecotoxicological risks. According to climate change models, expected increase of rainfall erosivity will enhance soil erosion and consequently the sediment flow to reservoirs, potentially increasing coarse grain fractions and thus potentially diluting pollutants. Conversely, increased weathering may enhance metal fluxes to reservoirs.

On the contrary, Zhai et al. (2017) face the problem emphasizing the water quantity. The author propose some adaptation strategies for the management of the water level of some cascade hydropower stations located along the Yangtze River, China under changing climatic conditions. It is suggested that cascade hydropower stations could be operated at a flood limited water level in the near future. In addition, the impoundment of cascade hydropower stations should be properly delayed during the post-flood season in response to the possible occurrence of increased and extended inflow in wet seasons.

Ren et al. (2017) describes, for the Manas River basin, northwest China, that the runoff will significantly increase from February to May in the next future, with the consequent rise of flood occurrence frequency. Management suggestions are provided for the hydropower stations located in the catchment.

Holmes et al. (2017) provides an interesting approach to mitigate future climate change impacts on quantity, quality, and timing of freshwater availability [13]. The authors suggest a method to identify natural storage reservoirs as valuable tools for increasing resiliency to these climate change impacts. Natural storage processes, such as the services provided by wetlands and floodplains, act to not only slow down water and raise the streambeds in incised and entrenched streams, but have also been shown to effectively attenuate and reduce high peak runoff during large flood events. The Musselshell River in central Montana, U.S.A., was selected as a broader study region due to the degree of collective participation and expressed interest from residents to reduce their vulnerability to water shortages and extreme flood events by collaborating with state agencies and academic institutions, and by exploring more environmentally integrated methods of natural water storage. This research produced a costand time-effective GIS-based method of estimating the water storage potential of the basin, and for identifying potentially viable natural storage sites using open source data.

\subsection{Adapting Strategies for Urban Areas}

Kumar et al. (2017) face the worsening of water quality which characterizes the most populous and rapidly developing regions, especially the megacities of Asia [14]. This situation is considered due to the overexploitation of groundwater, skewed water supply and demand due to population explosion, and the negative impacts of climate change. The area of interest for this research is the District of Jakarta (Indonesia). The authors explain that, in this region, deterioration of the surface water resources is caused by a confluence of uncoordinated brisk urban expansion, inadequate wastewater treatment facilities, low levels of awareness and fragile institutional capability of the concerned agencies, and huge amounts of wastewater. Under near future climatic scenarios, the authors propose 
to implement a national integrated sewerage and septage management program to improve the water quality.

Yuan et al. (2017) present an other Asian megacity: Shanghai, China. The authors describe that the city in this case suffers from the serious consequences of two climate change impacts: floods and sea level rise. Monitoring measurements combined with a database system on a website was found by authors to be useful for forecasting and simulating flooding hazards. Moreover, for systematic sustainable urban water system management, appropriate treatment technologies, such as a sustainable urban water system which can control and manage water quantity and quality, should also be considered [15].

\subsection{Adapting Strategies for Agricultural Areas}

Lee et al. (2017) analyzed the possible future impact of climate change on drought characteristics in the Hwanghae Province, which is a significant food source in North Korea. The results indicate that severe drought is more likely to occur in future. However, the same authors state that these results are strongly dependent on simulations from only one set of climate change data. There are therefore limitations due to the uncertainty in various climate change scenarios [16].

Zhou et al. (2017) studied the future effects of climate change on crop irrigation requirement in the Hetao irrigation district, China. This region is one of the largest irrigation districts in addition to being an important commodity grain production base in China. The results show that the crop irrigation requirement will increase because of the increase of the crop evapotranspiration and the decrease of effective precipitation [17].

Dlamini et al. (2017) evaluated the potential impacts of climate change on the streamflow of the Bernam River Basin, Malaysia. In the past, the rice scheme suffered frequent water shortage due to constraints on the delivery of water and timing and water management practices that led to inefficient use of water. The authors forecast a decreasing trend in streamflow during the dry season and an increasing pattern in the wet season. Therefore, the rice irrigation requirement will be enhanced [18].

\section{Discussion}

\subsection{Categorization of Climate Change Adaptation Studies}

A lesser-known success of the Paris climate agreement in 2015 is the 'global adaptation goal', an ambitious plan for adapting to climate change that reaches beyond national boundaries [19]. Because this plan by nature involves long-term objectives, some of the main questions raised in current adaptation research studies are whether and how these actions/projects will be implemented and what is required for these plans to successfully achieve their objectives [20]. This question calls for new methods and tools for adaptation studies. In fact, conceptual and empirical studies to date have shown that adaptation strategies face some important deficiencies compared to mitigation, such as the lack of consistent definitions and practices, agreed metrics, comparable baselines, standardized approaches to data collection, and robust guidance $[19,20]$.

This collection of papers aims to provide a contribution in this context. It contains 15 scientific studies facing a diversity of issues inherent to the adaptation strategies for water resources. The main outcomes relevant to the specific case studies have been pointed out in the previous section, while, in the following, an attempt is made to analyze how the authors have decided to develop and present their research.

The published papers in this Special Issue can be categorized in two major fields:

(1) Studies for the development of adaptation scenarios.

(2) Studies for the development of adaptation solutions.

The first category is born from a large body of recent literature addressing the concern about the potential impacts of climate change on water resources. These studies are generally named "Climate change 
impact studies" [21,22]. The standard framework of "Climate change impact studies" [23] usually considers the following research components:

(a) the definition of the emissions scenarios of greenhouse gases (usually provided by the Intergovernmental Panel on Climate Change, or IPCC) and the selection of a climate model and the downscaling processes;

(b) the application of impact (quantity and/or quality) models;

(c) the evaluation of skill and uncertainty of these models.

Papers which investigate even possible adaptation scenarios need to additionally consider:

(d) the identification of one or more adaptation solutions;

(e) the application of the impact models including the selected adaptation solution;

(f) the evaluation of skill and uncertainty of the adaptation scenario;

(g) the provision of implementation guidance to adaptation actions.

The second category considers those studied which identify a technique or a process useful to be used as adaptation solution. Usually, these kind of studies do not develop a future scenario which could be investigated in other specific studies, but rather provide specific technical, methodological, and procedural details on the proposed adaptation solution. Papers which develop adaptation solutions can consider:

(a) the detailed description of the solution and the context where it is proposed;

(b) the evaluation of skill and uncertainty of the adaptation solution;

(c) the provision of implementation guidance to adaptation actions.

Of 15 papers published in this Special Issue, 11 belong to the first category and 4 to the second category. Table 1 shows whether the research components presented above have been included in each paper.

Table 1. Categorization of papers published in this Special Issue in two groups: "Climate change impact-adaptation studies" and "Development of adaptation strategies". The possible inclusion in the paper of each research component (refer to the text for details) is shown.

\begin{tabular}{|c|c|c|c|c|c|c|c|}
\hline Authors & $\begin{array}{l}\text { Development } \\
\text { Climatic } \\
\text { Scenario }\end{array}$ & $\begin{array}{c}\text { Development } \\
\text { Impact } \\
\text { Scenario }\end{array}$ & $\begin{array}{l}\text { Uncertainty } \\
\text { Impact } \\
\text { Scenario }\end{array}$ & $\begin{array}{l}\text { Identification } \\
\text { Adaptation } \\
\text { Solutions }\end{array}$ & $\begin{array}{l}\text { Development } \\
\text { Adaptation } \\
\text { Scenario }\end{array}$ & $\begin{array}{c}\text { Uncertainty } \\
\text { Adaptation } \\
\text { Scenario }\end{array}$ & $\begin{array}{c}\text { Implementation } \\
\text { Adaptation } \\
\text { Scenario }\end{array}$ \\
\hline \multicolumn{8}{|c|}{ Studies for the development of adaptation scenarios } \\
\hline Guyennon et al., 2017 & $\mathrm{x}$ & $\mathrm{x}$ & $x$ & $\mathrm{x}$ & $\mathrm{x}$ & & \\
\hline Marziali et al., 2017 & $x$ & $x$ & $\mathrm{x}$ & & & & \\
\hline Zhai et al., 2017 & $x$ & $x$ & $\mathrm{x}$ & $\mathrm{x}$ & $\mathrm{x}$ & & \\
\hline Ren et al., 2017 & $\mathrm{x}$ & $x$ & $\mathrm{x}$ & & & & \\
\hline Kumar et al., 2017 & $x$ & $x$ & & & & & \\
\hline Lee et al., 2017 & $x$ & $x$ & & & & & \\
\hline Zhou et al., 2017 & $\mathrm{x}$ & $x$ & & & & & \\
\hline Dlamini et al., 2017 & $\mathrm{x}$ & $x$ & $x$ & & & & \\
\hline Ma et al., 2017 & & & & & & & \\
\hline Qi et al., 2017 & & & & & & & \\
\hline Luo et al., 2017 & & & & & & & \\
\hline \multicolumn{8}{|c|}{ Studies for the development of adaptation solutions } \\
\hline Holmes et al., 2017 & & & & $\mathrm{x}$ & & $\mathrm{x}$ & $x$ \\
\hline Yuan et al., 2017 & & & & $\mathrm{x}$ & & & \\
\hline Robert et al., 2017 & & & & $\mathrm{x}$ & & & \\
\hline McFadgen and & & & & & & & \\
\hline Huitema, 2017 & & & & $x$ & & & $x$ \\
\hline
\end{tabular}

\subsection{Studies for the Development of Adaptation Scenarios}

Starting analyzing the first category, it is clear that not one of them presents all the proposed research components. In particular, the discussion of uncertainty of the provision of implementation 
guidance to adaptation actions has never been faced. Only two studies $[9,11]$ identify, propose, discuss, and develop an adaptation scenario. Five other studies $[10,14,16-18]$ belong more properly to the category "Climate change impact studies". The last three studies [24-26] analyze changes that have occurred in the climate and with water resources in the recent past decades, without developing any future scenarios. However, in all these last eight studies, the component related to the "adaptation to climate change" is present, but not fully developed, i.e, they are unbalanced in favor of the assessment of future impacts and less towards the adaptation. Generally, these studies discuss future or past "climatic and the impact scenarios" and conclude briefly by suggesting what broadly could be done as adaptation solution. Surely, these studies provide a knowledge contribution, but they can probably be, in an adaptation context, considered only propaedeutic to real "climate change adaptation studies" which could eventually be developed more in depth in the future.

These considerations align with previous studies, which indicate that identifying approaches to addressing uncertainty is a weakness of adaptation strategies [27-29] and with those studies [28] affirming that that most plans fail to provide detailed implementation processes, raising concerns about whether adaptation actions will translate into reductions in vulnerability or maladaptation. Generally, considerable uncertainty in the timing, magnitude, and direction of climate change remains currently open [29], in particular for precipitation [30] and this uncertainty complicates adaptation actions [31]. Therefore, adaptation planning cannot avoid uncertainty [32], but must manage it, for instance by considering multiple climatic scenarios as a good practice (usually the ones provided by IPCC) [32,33]. Managing uncertainty may create action plans that remain relevant longer, allow for corrective action, and avoid maladaptive outcomes [29,34,35].

\subsection{Studies for the Development of Adaptation Solutions}

As far as the second category, we can observe that the study proposed by Holmes et al. (2017) fully addressed all three requirements proposed above for this category. I think that this paper is an excellent example of research devoted to providing a feasible adaptation solution towards a forecasted period of floods and droughts in central Montana, U.S.A., thought identification and estimation of natural floodplain water storage capacity. Future climatic, environmental, and social contexta are properly detailed as well as the proposed modeling technique. An uncertainty analysis is conducted, providing a list of data that could improve the accuracy of the storage modeling. The implementation aspects are considered, reporting the water right implications and interviewing stakeholders [13].

Robert et al. (2017) identify three types of farms in India which influence differently the watermanagement policies. Although the study represents a remarkable effort to improve the knowledge of the farm system, the definition of a specific adaptation solution is lacking, as well as the future climatic context for which it would have been developed. Consequently, no evaluation of uncertainty and provision of implementation guidance is proposed [36].

Yuan et al. (2017) propose a sustainable urban water system for Shanghai, China as adaptation solution to a possible further increase of the sea level and flooding events. Whereas climate and impact changes are properly presented for the recent past decades, no future scenario is reported. Therefore, no evaluation of uncertainty regarding adoption of the adaptation solution could be done, as well as no implementation guidance is proposed [15].

McFadgen and Huitema (2017) present an experimentation technique of "adaptive management" applied to the science-polity interface in a context of initiatives relevant to climate adaptation in the Netherlands [8]. A good proposal to identify solutions that work, as suggested generally in the "adaptive management" context. Policy actors who employ a "learning-by-doing" approach, where an idea is executed and evaluated to understand its impacts, are able to reduce the uncertainty of the system [37], i.e., as widely discussed above, the central weakness for the development of adaptation strategies to climate change. 


\section{Conclusions}

The implementation phase of the Paris Agreement has started, and scientific communities, more than ever before, should stay at the center of the framework; their task is to bridge the 'literature gap', to help close not only the mitigation gap, but also the adaptation gap. The Paris Agreement presents a unique opportunity for scientific communities to explore new fields of research, test ideas and hypotheses, and to find results that were not conceivable before its adoption. A challenge for future research consists in developing context-specific guidelines that will allow funding bodies to make the best decisions to support adaptation (i.e., by better capturing the risk of maladaptation) and practitioners to design adaptation initiatives with a low risk of maladaptation.

This Special Issue on "Adaptation strategy to climate change for water resources" is born in light of these recommendations. It contains 15 scientific studies facing a diversity of issues inherent to the adaptation strategies for water resources. The main outcomes relevant to the specific case-studies have been pointed out, but a further attempt has been made to analyze how the authors have decided to develop and present their research. A discussion proposed in order to identify some criteria to define, in the near future, standardized approaches for adaptation studies.

Scientific papers focused on "Adaptation strategy to climate change for water resources" have been categorized in two major fields: "Studies for the development of adaptation scenarios" and "Studies for the development of adaptation solutions". Papers belonging to both categories generally fail to address the uncertainty and implementation of the proposed adaptation strategies, as already pointed out in the previous literature. However, an example of correct treatment of the proposed adaptation solution is provided [13].

Studies investigating future adaptation scenarios (first category) are generally found to be unbalanced in favor of the assessment of future impacts on water resources and less towards the provision of adaptation scenarios. Furthermore, when studies investigating future adaptation scenarios do not provide elements to manage the uncertainty specifically related to the proposed adaptation solution, exploring uncertainty related to the climatic and impact scenarios (using different IPCC emission scenarios) is strongly recommended. Two examples of complete development of adaptation scenarios, at least as regards the climatic and impact scenarios, are provided by Guyennon et al. (2017) and Zhai et al. (2017).

Studies providing methodological and/or procedural examinations on the proposed adaptation solutions (second category) are recommend to suitably report the context (climatic, environmental, and social) for which the adaptation solution has been developed. A decrease in uncertainty and an easier implementation could be induced from this.

I hope that, from this collection of papers and this analysis, the emerging criteria could contribute in the near future to defining standardized approaches and practices for adaptation studies on climate change.

Acknowledgments: The author of this paper, who served as the guest-editor of this special issue, wishes to thank the journal editors, all authors submitting papers to this special issue, and the many referees who contributed to paper revision and improvement of the 15 published papers.

Conflicts of Interest: The author declare no conflict of interest.

\section{References}

1. UNFCCC (United Nations Framework Convention on Climate Change). The Cancun Agreements, FCCC/CP/2010/7/Add.1. 2010. Available online: http://unfccc.int/resource/docs/2010/cop16/eng/ 07a01.pdf (accessed on 18 October 2017).

2. UNFCCC (United Nations Framework Convention on Climate Change). The Paris Agreements, FCCC/CP/2015/7/L.9/Rev.1. 2015. Available online: https://unfccc.int/resource/docs/2015/cop21/ eng/109r01.pdf (accessed on 18 October 2017). 
3. Stephan, R.M. Climate change considerations under international groundwater law. Water Intern. 2017, 42, 757-772. [CrossRef]

4. Lesnikowski, A.; Ford, J.; Biesbroek, R.; Berrang-Ford, L.; Maillet, M.; Araos, M.; Austin, S.E. What does the Paris Agreement mean for adaptation? Clim. Policy 2017, 17, 825-831. [CrossRef]

5. Ourbak, T.; Tubiana, L. Changing the game: The Paris Agreement and the role of scientific communities. Clim. Policy 2017, 17, 819-824. [CrossRef]

6. Ford, J.D.; King, D. A framework for examining adaptation readiness. Mitig. Adapt. Strateg. Glob. Chang. 2015, 20, 505-526. [CrossRef]

7. Magnan, A.K.; Ribera, T. Global adaptation after Paris Climate mitigation and adaptation cannot be uncoupled. Science 2016, 352, 1280-1282. [CrossRef] [PubMed]

8. McFadgen, B.; Huitema, D. Learning our way out via Experimentation: A multi-case analysis of how design influences learning outcomes in policy experiments for climate adaptation. Water 2017, 9, 648. [CrossRef]

9. Guyennon, N.; Salerno, F.; Portoghese, I.; Romano, E. Climate change adaptation in a Mediterranean semi-arid catchment: Testing managed aquifer recharge and increased surface reservoir capacity. Water 2017, 9, 689. [CrossRef]

10. Marziali, L.; Tartari, G.; Salerno, F.; Valsecchi, L.; Bravi, C.; Lorenzi, E.; Genoni, P.; Guzzella, L. Climate change impacts on sediment quality of Subalpine reservoirs: Implications on management. Water 2017, 9, 680.

11. Zhai, M.Y.; Lin, Q.G.; Huang, G.H.; Zhu, L.; An, K.; Li, G.C.; Huang, Y.F. Adaptation of Cascade Hydropower Stations Scheduling on A Headwater Stream of the Yangtze River under Changing Climate Conditions. Water 2017, 9, 293. [CrossRef]

12. Ren, L.; Xue, L.; Shi, J.; Han, Q.; Yi, P.; Liu, Y. Study on Variations in Climatic Variables and Its Influence on runoff in Manas River Basin; China. Water 2017, 9, 258. [CrossRef]

13. Holmes, D.; McEvoy, J.; Dixon, J.; Payne, S. A Geospatial Approach for Identifying and Exploring Potential Natural Water Storage Sites. Water 2017, 9, 585. [CrossRef]

14. Kumar, P.; Masago, Y.; Mishra, B.K.; Jalilov, S.; Rafiei Emam, A.; Kefi, M.; Fukushi, K. Current assessment and future outlook of water resources considering climate change and a population burst: A case study of Ciliwung River, Jakarta City, Indonesia. Water 2017, 9, 410. [CrossRef]

15. Yuan, Y.; Xu, Y.; Arulrajah, A. Sustainable Measures for Mitigation of Flooding Hazards: A Case Study in Shanghai, China. Water 2017, 9, 310. [CrossRef]

16. Lee, S.; Yoo, S.; Choi, J.; Bae, S. Assessment of climate change impacts on drought characteristics in Hwanghae plain, North Korea through time-series SPI and SPEI: 1981-2100. Water 2017, 9, 579. [CrossRef]

17. Zhou, T.; Wu, P.; Sun, S.; Li, X.; Wang, Y.; Luan, X. Impact of future climate change on regional crop water requirement-A case study of Hetao Irrigation District, China. Water 2017, 9, 429. [CrossRef]

18. Dlamini, N.S.; Kamal, M.R.; Lai, S.H.; Bin Abdullah, A.F.; Bin Mohd, M.S.F.; Bin Mohd Soom, M.A. Modeling potential impacts of climate change on streamflow using projections of the 5 th assessment report for the Bernam River Basin, Malaysia. Water 2017, 9, 226. [CrossRef]

19. Magnan, A.K. Climate change: Metrics needed to track adaptation. Nature 2016, 530, 160. [CrossRef] [PubMed]

20. Olazabal, M.; Galarraga, I.; Ford, J.; Lesnikowski, A.; de Murieta, E.S. Towards Successful Adaptation: A Checklist for the Development of Climate Change Adaptation Plans; BC3 Working Paper Series 2017-01; Basque Centre for Climate Change (BC3): Leioa, Spain, 2017.

21. Vicuna, S.; Dracup, J.A. The evolution of climate change impact studies on hydrology and water resources in California. Clim. Chang. 2007, 82, 327-350. [CrossRef]

22. Soncini, A.; Bocchiola, D.; Confortola, G.; Minora, U.; Vuillermoz, E.; Salerno, F.; Viviano, G.; Shrestha, D.; Senese, A.; Smiraglia, C.; et al. Future hydrological regimes and glacier cover in the Everest region: The case study of the upper Dudh Koshi basin. Sci. Total Environ. 2016, 565, 1084-1101. [CrossRef] [PubMed]

23. Loehle, C. Criteria for assessing climate change impacts on ecosystems. Ecol. Evol. 2011, 1, 63-72. [CrossRef] [PubMed]

24. Ma, Q.; Zhang, J.; Sun, C.; Guo, E.; Zhang, F.; Wang, M. Changes of Reference Evapotranspiration and Its Relationship to Dry/Wet Conditions Based on the Aridity Index in the Songnen Grassland, Northeast China. Water 2017, 9, 316. [CrossRef]

25. Qi, P.; Zhang, G.; Xu, Y.; Wu, Y.; Gao, Z. Spatiotemporal Changes of Reference Evapotranspiration in the Highest-Latitude Region of China. Water 2017, 9, 493. [CrossRef] 
26. Luo, M.; Meng, F.; Liu, T.; Duan, Y.; Frankl, A.; Kurban, A.; De Maeyer, P. Multi-Model Ensemble Approaches to Assessment of Effects of Local Climate Change on Water Resources of the Hotan River Basin in Xinjiang, China. Water 2017, 9, 584. [CrossRef]

27. Berke, P.; Lyles, W. Public risks and the challenges to climate-change adaptation: A proposed framework for planning in the age of uncertainty. Cityscape 2013, 15, 189-216.

28. Woodruff, S.C.; Stults, M. Numerous strategies but limited implementation guidance in US local adaptation plans. Nat. Clim. Chang. 2016, 6, 796-802. [CrossRef]

29. Woodruff, S.C. Planning for an unknowable future: Uncertainty in climate change adaptation planning. Clim. Chang. 2016, 139, 445-459. [CrossRef]

30. Guyennon, N.; Romano, E.; Portoghese, I.; Salerno, F.; Calmanti, S.; Petrangeli, A.B.; Tartari, G.; Copetti, D. Benefits from using combined dynamical-statistical downscaling approaches-Lessons from a case study in the Mediterranean region. Hydrol. Earth Syst. Sci. 2013, 17, 705-720. [CrossRef]

31. Hallegatte, S. Strategies to adapt to an uncertain climate change. Glob. Environ. Chang. 2009, 19, $240-247$. [CrossRef]

32. Kwakkel, J.H.; Walker, W.E.; Haasnoot, M. Coping with the wickedness of public policy problems: Approaches for decision making under deep uncertainty. J. Water Res. Plan. ASCE 2016, 142, 1816001. [CrossRef]

33. Dittrich, R.; Wreford, A.; Moran, D. A survey of decision-making approaches for climate change adaptation: Are robust methods the way forward? Ecol. Econ. 2016, 122, 79-89. [CrossRef]

34. Lempert, R.J.; Schlesinger, M.E.; Bankes, S.C. When we don't know the costs or the benefits: Adaptive strategies for abating climate change. Clim. Chang. 1996, 33, 235-274. [CrossRef]

35. Walker, W.; Haasnoot, M.; Kwakkel, J. Adapt or perish: A review of planning approaches for adaptation under deep uncertainty. Sustainability 2013, 5, 955-979. [CrossRef]

36. Robert, M.; Thomas, A.; Sekhar, M.; Badiger, S.; Ruiz, L.; Willaume, M.; Leenhardt, D.; Bergez, J. Farm Typology in the Berambadi Watershed (India): Farming Systems Are Determined by Farm Size and Access to Groundwater. Water 2017, 9, 51. [CrossRef]

37. Lee, K.N. Conservation Ecology: Appraising Adaptive Management. Conserv. Ecol. 1999, 3, 3. [CrossRef]

(C) 2017 by the author. Licensee MDPI, Basel, Switzerland. This article is an open access article distributed under the terms and conditions of the Creative Commons Attribution (CC BY) license (http:/ / creativecommons.org/licenses/by/4.0/). 